\title{
Reference Values for Automated Cytochemical Differential Count of Leukocytes in Children 0-16 Years Old: Comparison with Manually Obtained Counts from Wright-Stained Smears
}

\author{
By E. Cranendonk, A. H. van Gennip, N. G. G. M. Abeling, H. Behrendt
}

Children's hospital Het Emma Kinderziekenhuis, Amsterdam and

\section{A. A. M. Hart}

Antoni van Leeuwenhoekziekenhuis, the Netherlands Cancer Institute, Amsterdam. The Netherlands

(Received October 18, 1984/May 20, 1985)

Summary: Reference values for the differential leukocyte count using an automated cytochemical method (Hemalog D) were determined in 1216 healthy children aged 0-16 years. Log-normal distributions for the absolute counts of all the separate cell types and for the total leukocyte counts were determined. For the relative values, a log-normal distribution for the eosinophils and basophils was also established. The Hemalog $\mathrm{D}$ gives narrower limits compared with the manual count, but the differences between the two methods are smaller than expected. It appears that the lower limit of the separate cell types is not zero.

Referenzwerte für das mit dem Hemalog D automatisch erstellte cytochemische Differentialblutbild von Leukocyten bei Kindern von der Geburt bis zum 16. Lebensjahr

Zusammenfassung: Bei 1216 gesunden Kindern im Alter von 0 bis 16 Jahren wurden mit dem Hemalog D Referenzwerte für das Differentialblutbild der Leukocyten cytochemisch automatisch bestimmt. Die Absolutwerte für alle einzelnen Zelltypen und die Gesamt-Leukocytenzahl waren log-normal verteilt. Auch für die Relativwerte der eosino- und basophilen Leukocyten wurde eine log-normale Verteilung festgestellt. Der Hemalog D ergibt, verglichen mit der morphologischen Bestimmung engere Bereiche; die Differenzen zwischen beiden Methoden sind jedoch geringer als erwartet. Der untere Bereich für die einzelnen Zelltypen scheint nicht null zu sein.

\section{Introduction}

The haematology laboratory of our hospital uses the. Hemalog D (Technicon Instr. Corp., Tarrytown, N. J.) for the differential count of leukocytes in peripheral blood. This instrument uses criteria different from the classical, i. e. morphological; therefore it is necessary to compare the data obtained from this instrument with those obtained with the classical method.

The Hemalog D differentiates the leukocytes in three channels on the basis of cell volume and specific stains: peroxidase, esterase and heparin stains. At the same time the total number of leukocytes is counted $(1,2)$. In view of the principles used for analysis and the large number of cells counted, different reference values with narrower limits are to be expected. The presently used values for children, as presented in many textbooks, are based mainly on investigations done in the thirties and fifties $(3,4,5)$. For example, Nathan \& Oski (1981) (6) refer to Dallman (1977) (7), but Dallman refers to Albritton (1952) (8). However Albritton mentioned that the given values are from smoothed curves plotted from averages of means from the literature. The literature used was not mentioned. The results of many of those in- 
vestigations cannot be compared with each other, owing to differences in, among other things, staining methods and statistical analysis. Also, there was no agreement on the type of distribution of the separate cell types. Several frequently quoted authors did not state or test a special type of distribution, but their presentation of the results suggests the assumption of a certain type of distribution. Sometimes the results were logarithmically transformed, for example as reported by Orfanakis (9) for the results from adults. Xunthou (10) tested her results from 69 neonates and found a log-normal distribution for the lymphocytes and eosinophils and a normal distribution for the other cell types. Therefore, for optimal comparison of the Hemalog D values with the classical reference values, it is not enough to compare them with the data obtained from the literature. Moreover, changes in the reference values can occur as a result of, for example, changes in the conditions of life. For these reasons all blood samples were also analysed by means of the classical method.

\section{Subjects}

Blood samples from 1216 healthy children aged $0-16$ years were analysed. These children came from a maternity ward, centres for child care, day nurseries and schools.

\section{Methods}

For analysis, capillary blood anticoagulated with EDTA was used. The total leukocyte count was determined with the Hemac 630 L Laser Hematology Counter (Ortho, Raritan, N. J.). Each sample was analysed with the Hemalog D. In addition. freshly prepared Wright-stained smears of each sample were analysed microscopically for comparison. Only films of good quality were examined. In each smear 100 leukocytes were differentiated. For the daily calibration of the leukocyte count with the Hemalog $D$, a sample of a healthy donor was analysed with the Hemac. Daily calibration of the Hemac was performed with a blood sample from a healthy donor, in which the total leukocyte count was established manually in duplicate by five laboratory technicians. The scattering allowed between duplicate values was $5 \%$. The Hemalog $\mathrm{D}$ was adjusted to the Hemac value and subsequently the same sample was analysed with the Hemalog D.

\section{Statistical analysis}

For each parameter the analysis was performed as follows: By 2-way analysis of variance we determined whether there was a difference between the values for boys and girls or between the values from the age groups. We also investigated whether there was an interaction between sex and age (i.e. whether the differences between the age groups were the same in boys and girls). The significance level $\mathrm{p}<0.05$ was used in all analyses. If no interaction was found and there was no difference between boys and girls, then the values for boys and girls within the same group were taken together. Subsequently, we determined, via the Duncan procedure (11), which of the consecutive age groups could be taken together. This procedure ensures that within the merged groups no statistical differences are found.
For each group formed in this way we checked whether the parameters might be regarded as normally or log-normally distributed. Depending on the distribution, the $95 \%$ tolerance limits were then determined. The SPSS statistical package (12) was used for all analyses.

\section{Results and Discussion}

All blood samples were obtained from apparently healthy children. Moreover, smears from all blood samples were checked for morphological abnormalities, and differential counts were performed manually. As can be seen in table 1, the analysis of variance of the obtained values showed significant sex-dependent differences for the absolute neutrophil count, and the relative basophil count. Moreover a sex-age interaction was found for the relative neutrophil counts, for the relative lymphocyte count estimated by Hemalog $\mathrm{D}$ and for the relative as well as the absolute large unstained cell (LUC) values.

In the Duncan procedure only incidentally boys and girls of the same age fell into significantly different groups; therefore we did not divide the values of boys and girls.

Tab. 1. $P$ values obtained from 2-way analysis of variance of the differential count for children 0-16 years old (significant differences are printed in bold type).

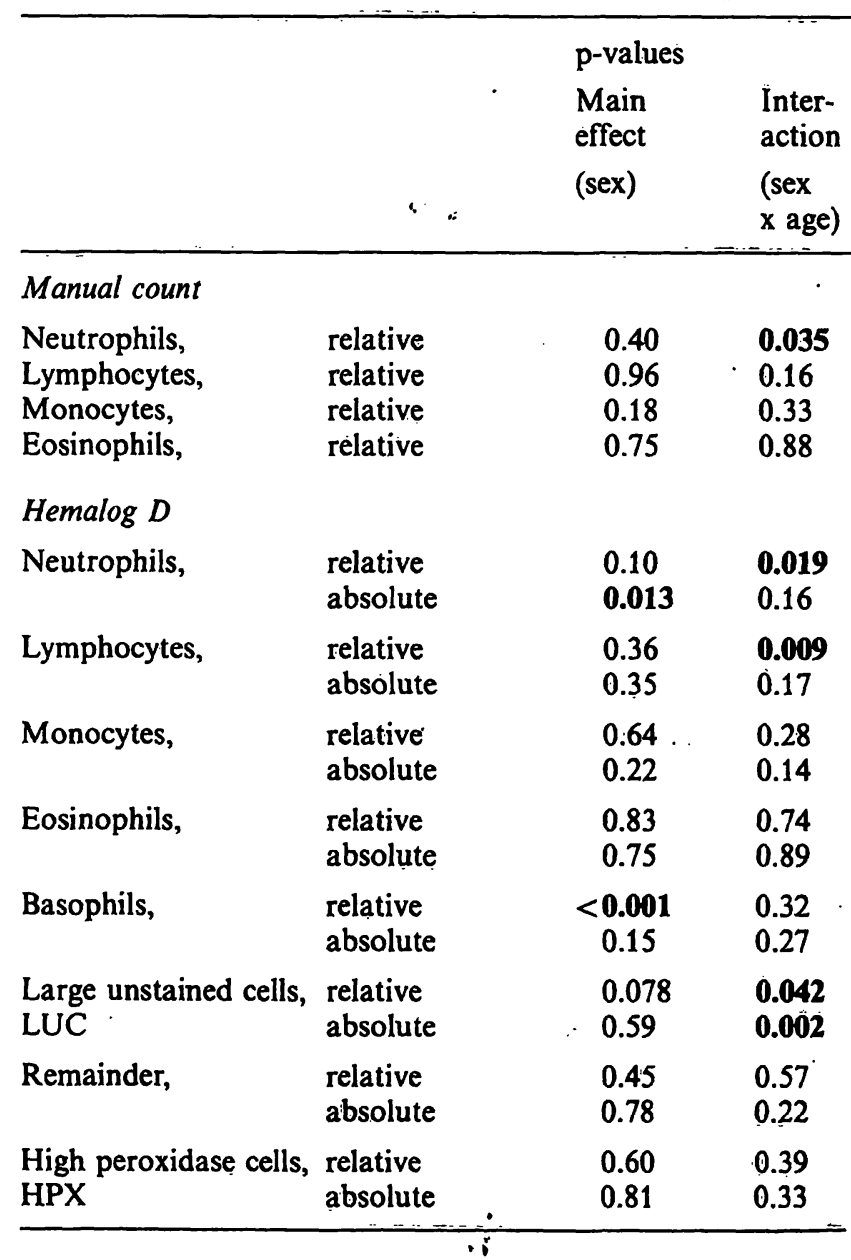




\section{Absolute values}

Our investigation shows that the total leukocyte count and all the separate cell types were log-normally distributed. As a consequence, at the lower limit of these reference values the distribution curve falls off more sharply than at the upper limit. It is interesting to notice that the lower limit for the basophils as analysed with the Hemalog D was almost the same as that found by Shelley \& Parnes (13), namely $20 \cdot 10^{6} / 1$.

\section{Relative values}

For the eosinophils in the manual count and for the eosinophils and basophils in the Hemalog D count we found a log-normal distribution. High peroxidase cells (HPX) and large unstained cells (LUC) were also log-normally distributed. For the basophils and the band cells, both obtained with the manual method, the distribution was neither normal nor lognormal because the mode of the distribution lies at zero. The distribution of the neutrophils and the lymphocytes was normal in the manual count as well as in the Hemalog D count. The ranges are presented in table 2 and 3.

It appears that the Hemalog $\mathrm{D}$ indeed gives narrower limits for the relative values compared with the manual count, but the differences are much smaller than expected. The upper limit for the neutrophils and the lower limit for the lymphocytes were nearly the same in both differential counts. The upper limit for the lymphocytes was somewhat lower and the lower limit for the neutrophils somewhat higher in the Hemalog $D$ differential count. As for the eosinophils, the upper limit was lower in the Hemalog D count, but only for children 9 years of age and older.

However, the Hemalog D has advantages over the manual method, because it now appears that the leukocytes do have a log-normal distribution and that the lower limit of the separate cell types is not zero. This will make it possible for the clinician to discern a shortage of eosinophils or basophils. Aneosinophilia and basopenia have been described in various disorders $(14,15)$. In most newborns the Remainder is often positive. Manual re-examination of these samples showed that many of these monocytes are esterase negative (16) indicating that these cells are immature.

For the relative neutrophil count lower values were found for the age group $0-3$ years in comparison with other age groups. The reverse situation can be mentioned for the relative as well as for the absolute lymphocyte counts. These phenomena are well known

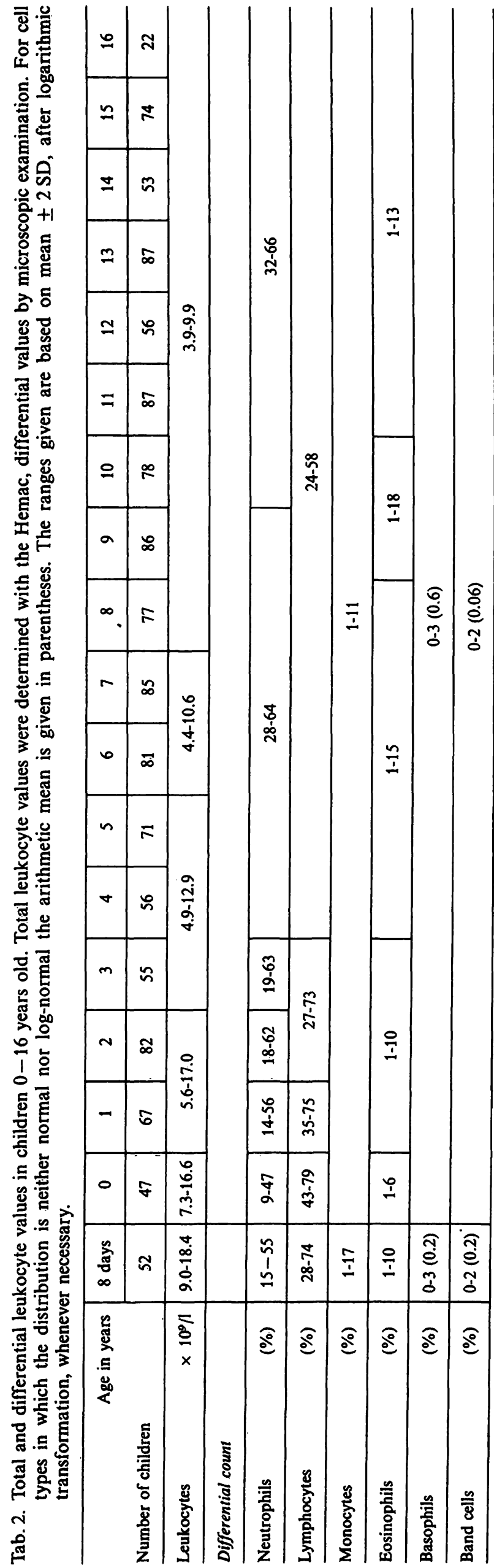




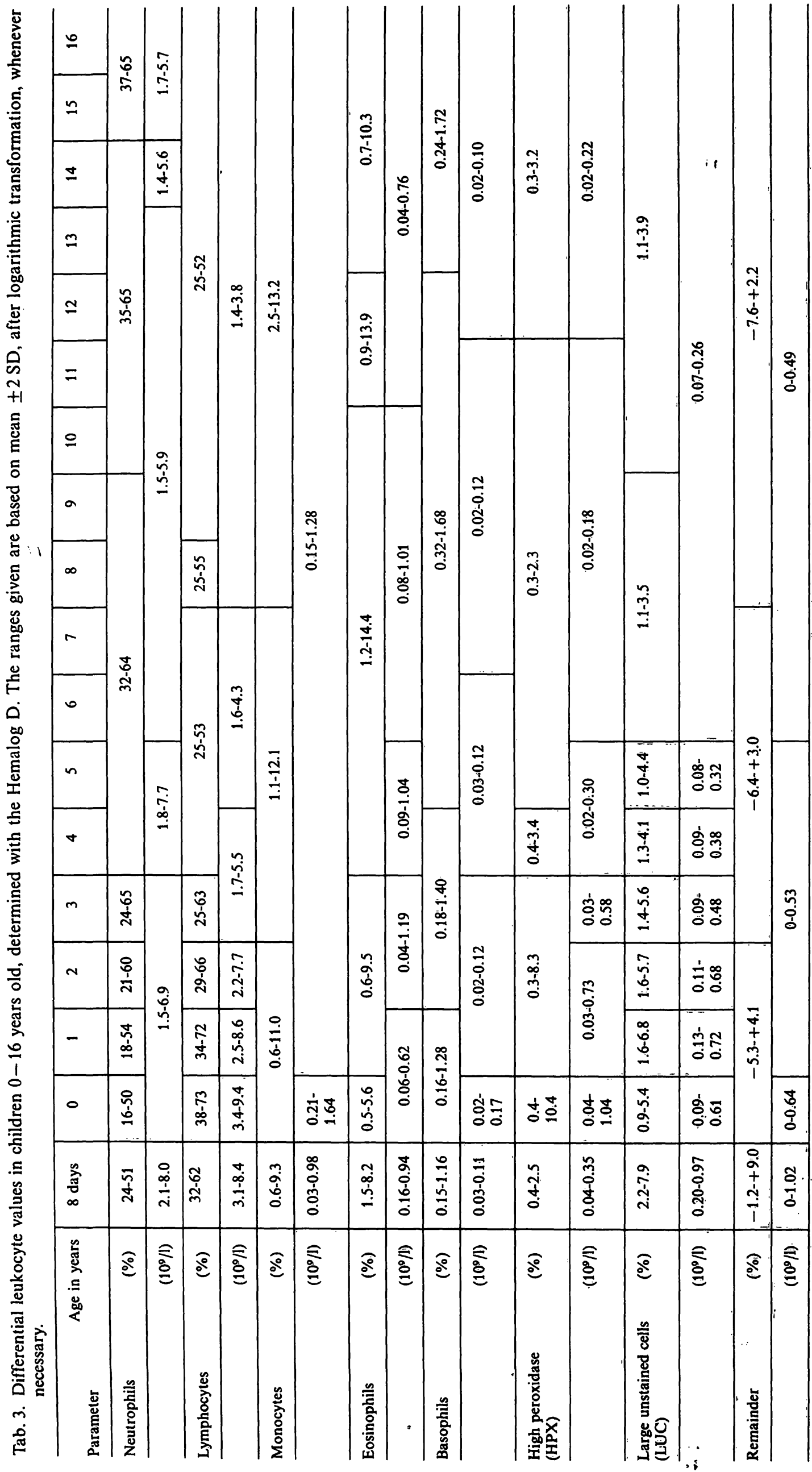


and related to the physiological hyperplasia of the lymphoid system during the first years of life. An interesting finding is the high upper limit for the high peroxidase cells (HPX) values in children $0-3$ years old, indicating the relative immaturity of the neutrophils in these young children.

\section{References}

1. Cairns, J. W., Healy, M. J. R., Stafford, D. M., Vitek, P. \& Waters, D. A. W. (1977) J. Clin. Pathol. 30, 997-1004.

2. Simmons, A., Leaverton, P. \& Elbert, G. (1974) J. Clin. Pathol. 27, 55-58.

3. Osgood, E. E., Baker, R. L., Brownlee, I. E., Osgood, M. W., Ellis, D. M. \& Cohen, W. (1939) Am. J. Dis. Child. 58, $282-294$.

4. Osgood, E. D., Baker, R. L., Brownlee, I. E., Osgood, M. W.. Ellis, D. M. \& Cohen, W. (1939) Am. J. Dis. Child. $58,61-70$.

5. Kato, K. (1935) J. Pediatr. 7, 7-15.

6. Nathan, D. G. \& Oski, F. A. (eds.) (1981) In: Hematology of infancy and childhood. p. 1563, W. B. Saunders Company, Philadelphia, London, Toronto.

7. Dallman, P. R. (1977) In: Pediatrics 16th Ed. (Rudolph, A. M., ed.) p. 1178, Appleton-Century-Crafts Inc., New York.

\section{Acknowledgement}

The authors are indebted to Mrs. Trudy van Denderen-Bosse and Mrs. Lida Stroomer for excellent technical assistance.

This investigation was supported by a grant from the Koningin Wilhclmina Fonds, the Dutch cancer foundation.
8. Albritton, E. C. (ed.) (1952) In: Standard Values in Blood. pp. 50-51, W. B. Saunders Company, Philadelphia and London.

9. Orfanakis, N. G., Ostlund, R. E., Bishop, C. R. \& Athens, J. W. (1970) Am. J. Clin. Pathol. 53,647-651.

10. Xanthou, M. (1970) Arch. Dis. Child. 45, 242-249.

11. Duncan, P. B. (1955) Biometrics $11,1-42$.

12. Nie, N. H., Hull, C. H., Jenkins, J. G., Steinbrenner, K. \& Bent, D. M. (1975) In: Statistical Package for the Social Sciences, McGraw-Hill, New York.

13. Shelley, W. B. \& Parnes, H. M. (1965) J. Am. Med. Ass. 192. $108-110$.

14. Juhlin, L. \& Michac̈lsson, G. (1977) Lancet $I, 1233-1235$.

15. Juhlin, L. (1963) Acta. Med. Scand. 174, 249-255.

16. Debauche, R. (1978) In: Proceedings of ACHE Workshop I, p. 106, Brugge.

H. Behrendt

Emma Kinderziekenhuis

Spinozastraat 51

NL-1018 HJ Amsterdam 
